\title{
From TLS Recoding to VR Environment for Documentation of the Governor's Tombs in Dayr al-Barsha, Egypt
}

\begin{abstract}
The governors tombs located at Dayr al-Barsha are ranked among the most important heritage sites of the Egyptian Middle Kingdom. Unfortunately, the site underwent transformations and was affected by ancient quarrying, looting, and natural disasters such as earthquakes, thus bringing this archaeological site on the edge of ruin. For this reason, its digital documentation is important and valuable for the preservation and further study of this elite cemetery. This paper describes the work-flow towards the 3D digital recording and full immerse visualization of the monuments that compose this ancient site. These stages include the physical recording using Terrestrial Laser Scanners (TLS), the creation of realistic 3D models from the acquired data, and the creation of a Virtual Reality (VR) world of the most paramount burial monument of this archaeological area. The obtained digital representation of the site will not only serve as a basis for geoarchaeological surveying and analysis, but also as a digital tool for public disclosure of the archaeological remains.

\section{Index Terms: \\ Heritage Documentation-Remote Sensing-Virtual Reality- Photogrammetry}

\section{INTRODUCTION}

Dayr al-Barsha is a village in Middle Egypt, located on the east bank of the Nile, opposite the town of Mallawi. The plateau which neighbors the village hosts one of the most important monuments of the Egyptian Middle Kingdom (ca. 2050-1650 B.C.): The Governor's Tombs. This archaeological site provides rich information of the middle kingdom era, as a wide range of the archaeological remains contain visual content that describes events that defined the course of Egyptian history. However, due to quarrying and looting activities, this Egyptian monument is now in a ruinous state. Therefore, a comprehensive and reliable three-dimensional documentation of the site becomes an advisable task for the preservation, and deeper research of the site.

Remote Sensing sensors and techniques have supported the documentation of archaeological monuments by offering an accurate alternative to traditional measurement and recording methods. With the advent of cutting edge sensors, 3D modeling engines, and Virtual Reality platforms, the gap between exhaustive documentation of complex heritage sites and its full-immersion visualization is now bridged. Motivated by the above, the 3D digital documentation work-flow of the governor's tombs is described in this paper. From physical acquisition using Terrestrial Laser Scanners and postprocessing of the data acquired, to the realistic-based model creation of the most paramount tomb, and its instantiation into a web-based VR world (see Figure 1).

This paper is organized as follows. Section 2 describes the potential applications of 3D digital documentation in the context of heritage monuments. After that, a brief description of the governor's tombs is given in Section 3. The detailed description of the TLS-based recording campaign is provided in Section 4. The 3D modeling approach of Djehotihotep's tomb and the VR environment

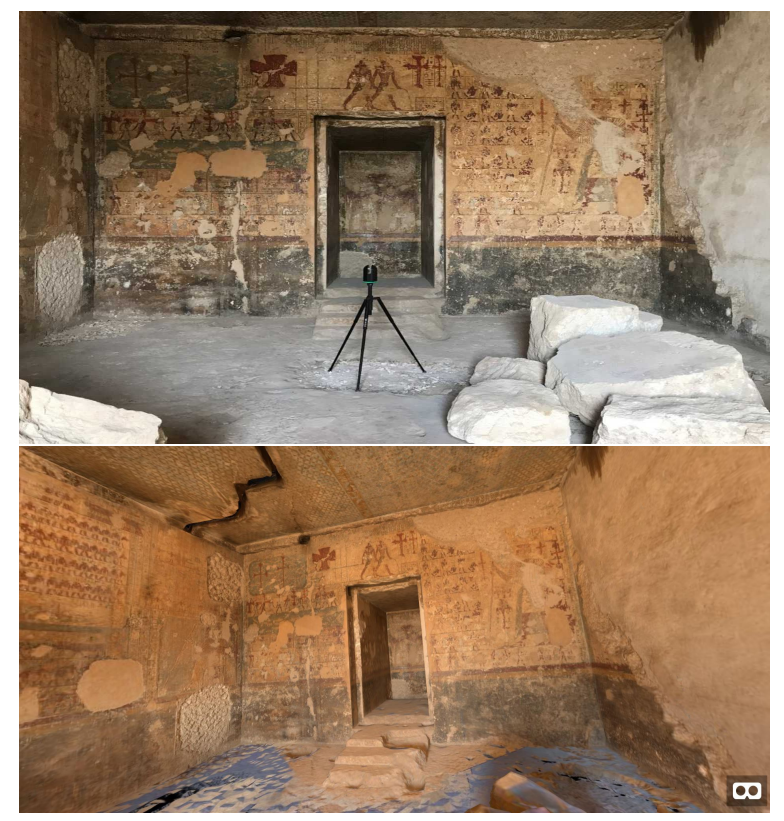

Figure 1: TLS-based recording of the most decorated tomb (top), and its 3D mesh model into a web-based VR world (bottom).

development is described in section 5. Finally, the possible research applications of the acquired data, and conclusions are discussed in Sections 6 and 7.

\section{Related Work}

Technological advancements are increasingly widening the spectrum of $3 \mathrm{D}$ acquisition techniques and sensors. As proved in several case studies, TLS and photogrammetry have gained a place in the field of heritage documentation as reliable approaches for 3D digital recording [18]. TLS-based geomatics techniques have replaced traditional methods for the spatial documentation of heritage monuments [21] as they offer metric accuracy and a 3D dense representation of the world, on the basis of which experts are able to analyze and perform measurements of the site in a more accurate way. In [11], TLS output data is employed to perform detailed cross-sectional drawings of architectural features, providing archaeologist with a digital tool that serves as a basis for further research and excavation planning, since the drawings are scaled and accompanied with distance measurements. By employing surveying techniques, the point-clouds obtained from TLS recording campaigns $[11,19,24]$ are georeferenced, so that the resulting 3D models support geoarchaeological research while becoming promising analysis frameworks for the $3 \mathrm{D}$ distributions of archaeological findings. In $[8,27]$, TLS pointclouds are used to compute realistic models of ancient artifacts, objects, and sites by means of the well-known process of meshing [2]. This procedure transforms the recorded 3D points into a set of textured polygons, increasing the level of realism of the model. Aside from visualization purposes, these digital models could be exploited for geometric analysis and their derived applications [17], 
such as: restoration and preservation support, heritage monitoring, object interpretation, etc.

Photogrammetry, on the other hand, is an affordable approach for the 3D digital acquisition of objects and sites. Since the main principle behind this digitalization method focuses on texture quality rather than on metric accuracy, most researchers employ this strategy only for visualization purposes $[3,9]$. In pursuit of expanding the range of $3 \mathrm{D}$ recording data applications, the symbiosis between TLS and photogrammetry is emerging as a 3D digitalization approach that exhibits a good trade-off between detailed texture and spatial resolution for the documentation of heritage monuments [7]. This combined approach improves the reliability of those research applications that require high quality surveying descriptions such as: damage assessment [6], detailed monitoring of standing monuments [16], and photo-realistic three-dimensional surveys [25].

Although digital acquisition is a primordial step towards a comprehensive documentation of cultural monuments, the potential of the digital content is only fully reached when it is provided to the user in an interactive way. VR equipment and virtual environments have enriched the interaction between users and digitized entities in different application domains, amongst which also cultural heritage. Virtual museums [12], educational games citeMortara2014, and full-immersion interactive visualizers [5], are some examples of the applications that exploit this emergent technology to make digital heritage material accessible to experts and non-experts, allowing for the interactive exploration and research of the documented data, and encouraging general public to immerse in the past.

The 3D digital documentation work-flow proposed in this research takes advantage of the aforementioned benefits provided by these emergent technologies. Surveying techniques are combined with TLS recording in order to obtain millions of georeferenced points, that represent a reliable description of the Governor's tombs. From this basis, those points that belong to one of the most representative monuments of the site are gathered and combined with imagery content using photogrammetric techniques. This results in a 3D model that is translated into a VR world to bridge the gap between physical acquisition and digital visualization.

\section{Description of the Site}

The Dayr al-Barsha rock hills that host the elite cemetery and the layout of its archaeological monuments are depicted in Figure 2. On the top, dotted lines enclose the plateau area where the middle kingdom governor's tombs are located. On the bottom, the map offers a dimensional and cardinal perspective of the archaeological site. This cemetery is composed of eight governor's tombs, one ancient quarry located on the extreme west, and various burial shafts - the small rectangles marked with crosses - that belonged to the family and attenders of the governors [26]. The site is not accessible to tourists, but the KU Leuven University has the archaeological concession to study the ancient cemetery area of Dayr al-Barsha. Over the years this has lead to a vast compilation of archaeological findings, hand measurements, and findings, resulting from the expeditions. However, the digital documentation of the site represents a challenge because of the current dilapidated condition of the tombs and the difficult accessibility of the burial shafts. Hence, two main aspects have to be considered for its recording. On the one hand, the use of portable equipment is primordial to avoid jeopardizing the archaeological integrity of the monuments. On the other hand, climbing equipment and lighting devices are necessary to have access to the burial monument as they go from 3 up to $12 \mathrm{~m}$ deep.

\section{TLS RECORDING}

The TLS recording expedition was carried out during the March 2018 campaign, within the framework of Dayr a-Barsha Project [14]. A Leica BLK 360 terrestrial laser scanner was chosen for the data acquisition because of its characteristics of portability (Height: 165

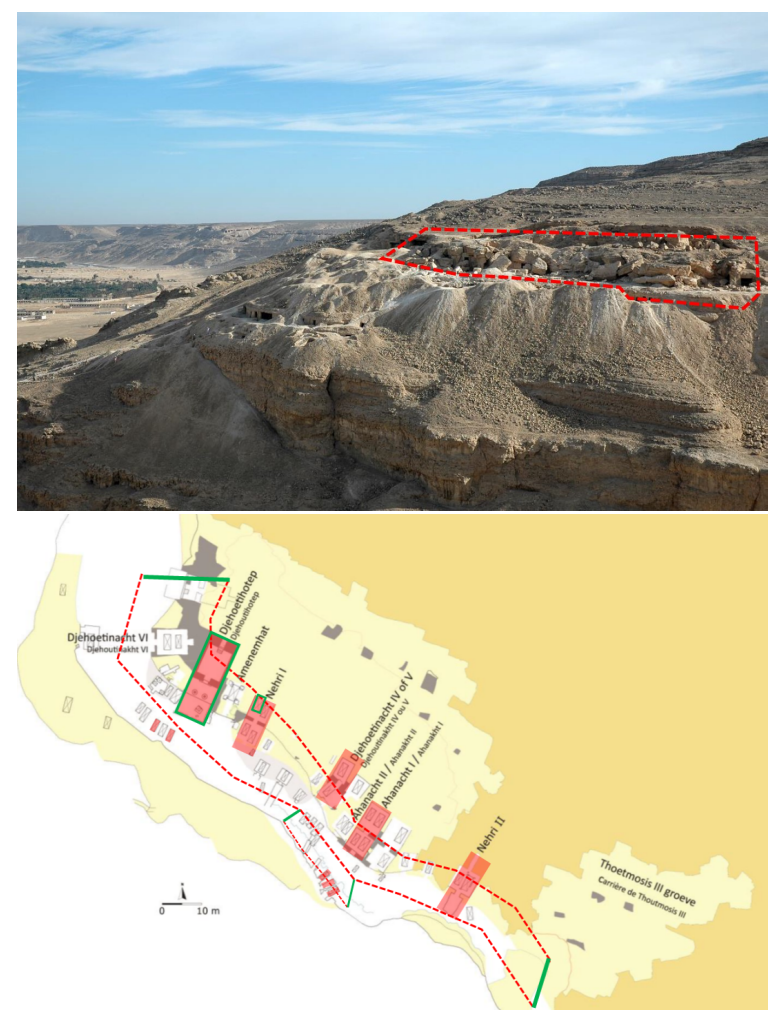

Figure 2: Top. The governor's tombs plateau marked with red dotted lines. Bottom. Trajectory of scanner displacements followed for the general recording of the site.

$\mathrm{mm}$, Diameter: $100 \mathrm{~mm}$, Weight: $1 \mathrm{~kg})$, and spatial resolution $(4 \mathrm{~mm}$ @10m/7mm@20m). The recording of the site was performed following a general-to-particular strategy. First, an overall perspective of the governor's tombs was scanned, including georeferencing control points. Then, complex scenarios such as decorated chapels, burial shafts, and attenders tombs were processed independently. Finally, all the scans were aligned into the same reference system based on the overlap with the goreferenced point-cloud computed in the first stage.

For the overall recording of the site, dotted red lines in Figure 2 (bottom) show the trajectory of the scanner locations. The elongated shape of the site may intuitively lead to linear recording paths. Because the registration of the scans is done using cloud-to-cloud algorithms, this may give rise to substantial drift errors. In order to prevent this, we foresee overlapping areas between the frontal and upper scans (green lines). This allows us to close the loops and improves the point-cloud alignment in terms of both global and cloud-to-cloud error, minimizing the accumulative error and guaranteeing an undistorted result. In total, 199 scans at standard resolution (10mm @10m) were acquired and accompanied with panoramic HDR pictures for later integration with high definition imagery content. This forms the basis for the generation of realisticbased models, as described in section 5. In order to georeference the recording data, four of the scans are set-up so that physical control points (measured in previous missions) are visible in the scan, thus allowing us to geographically locate the scans in the local coordinate system of the site.

In the second stage of the recording campaign individual burial monuments were scanned, more specifically the inner tombs chapels and their respective burial shafts. The map of Figure 2 depicts these monuments highlighted by red sections. For the sake of exemplifica- 


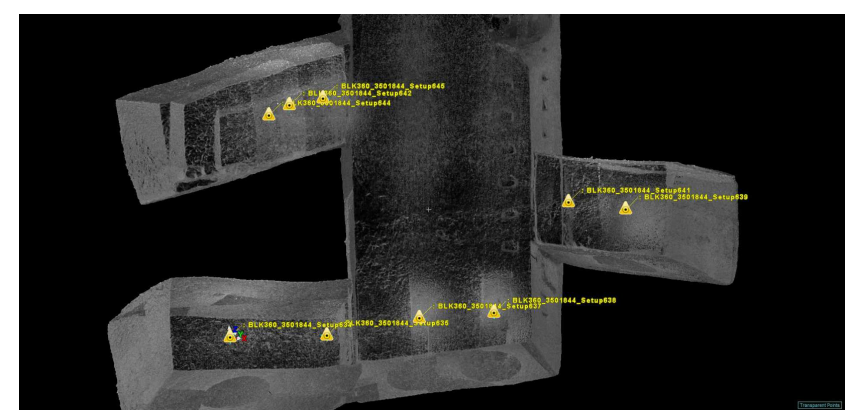

Figure 3: Cloud silhouette and scanner setups (yellow triangles) of the illustrative burial shaft belonging to the tomb of Nehri I

tion, we describe the scanning process of the tomb of Djehutihotep, the most well-preserved tomb, and one of the burial shafts belonging to the tomb of Nehri I, both marked with green lines. In the interior of the former monument, big collapsed decorated fragments have remained immobile to avoid compromising their archaeological integrity. Therefore, six scan locations were set up across the chamber to avoid occlusion by the collapsed stones and to capture all the hidden spots, as shown in Figures reffig:tomb a/b. The resulting point-cloud of the illustrative burial shaft is shown in Figure 3, yellow triangles point out the scanning positions required for the complete recording of the shaft. Note that the scanner is set up on the edge of the small chambers to obtain overlapping point-clouds thus, facilitating the alignment process. The scans are captured at standard resolution without color content, since texture information is not relevant for the study of this monument and lighting conditions were very poor.

Leica's registration software package Cyclone [13] was used for post-processing the acquired data. First of all, each scan was meticulously filtered in order to remove unwanted scanned points, such as big stones lying on the bottom of the shafts, auxiliary excavation personnel, etc. Then, the scans were aligned into the same coordinate system by means of a cloud-to-cloud registration strategy. This process consisted in visually aligning pairs of scans and then employing the Iterative Closest Point (ICP) [20] algorithm to minimize the distance between overlapping point-clouds. Given the large quantity of recorded data, the registration process was conducted using the following work-flow. Firstly, the set of scans that corresponds to the general perspective of the site, were registered and georeferenced, resulting in a point-cloud that served as a basis for the registration of subsequent scans. Secondly, the remaining scans were grouped and processed by monuments, aiming at obtaining complete 3D models for each archaeological element without accumulating a global registration error. Finally, all scans were aligned with respect to the georeferenced point-cloud. Figure $4 \mathrm{c}$ shows the West top view of the governor's tombs, where the forecourt of Djehutihotep's tomb is distinguishable. Figure $4 \mathrm{~d}$ depicts four burial shafts of the tomb of Nehri I from an underground perspective.

The total number of points after filtering unwanted information is $161,212,0287$. The mean absolute registration error is $0.004 \mathrm{~m}$. Since there exists less overlap between burial shafts scans, their registration exhibits the max error, between $0.009 \mathrm{~m}$. and $0.014 \mathrm{~m}$.

\section{TOMB OF DJEHUTIHOTEP IN VR}

The previous section described the TLS recording and data processing used to obtain a georeferenced point-cloud of the governor's tombs. As mentioned, this 3D representation is fundamental for the deeper study of the site via different data analysis tools, one of which is the exploration of archaeological monuments by means of full-immersion Virtual Reality worlds. This section describes the process for developing a web-based VR environment of the Tomb of

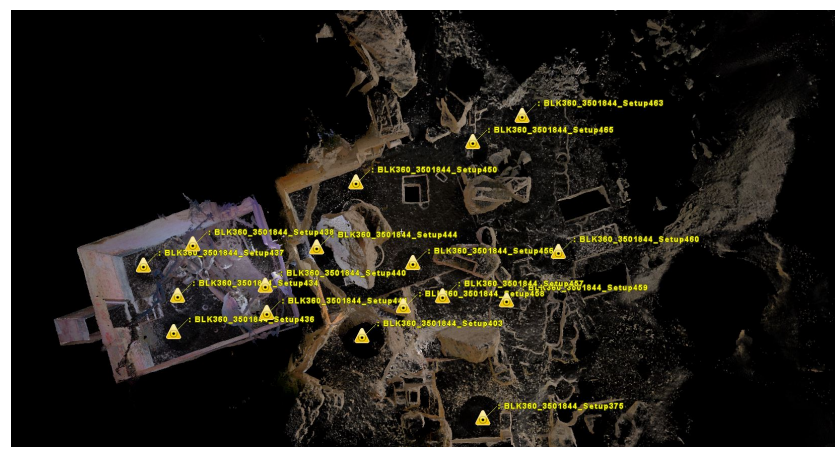

(a)

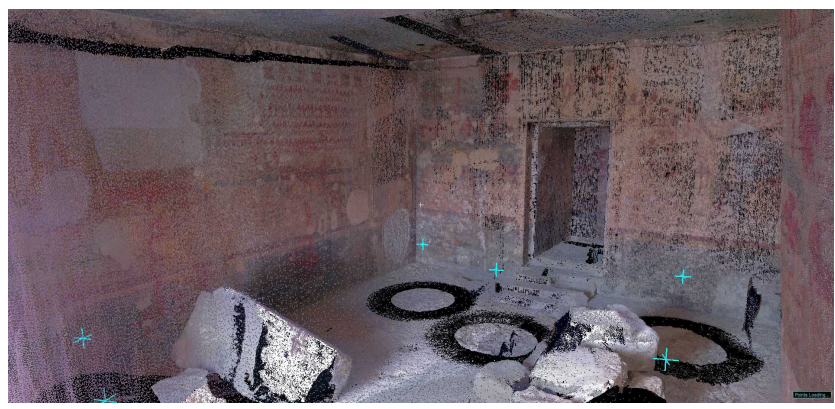

(b)

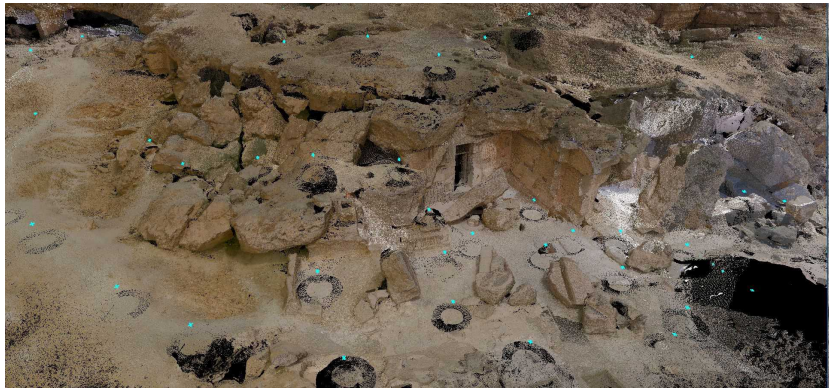

(c)

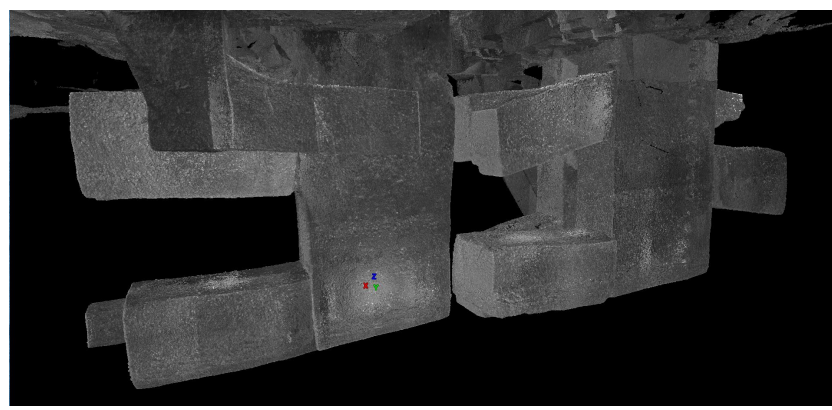

(d)

Figure 4: (a) Scanner setups for the recording of Djehutihotep's tomb. (b) Inner chamber recording of Djehutihotep's tomb. (c) Top perspective of the registered western points. (d) Underground view of the tomb of Nehri I. 

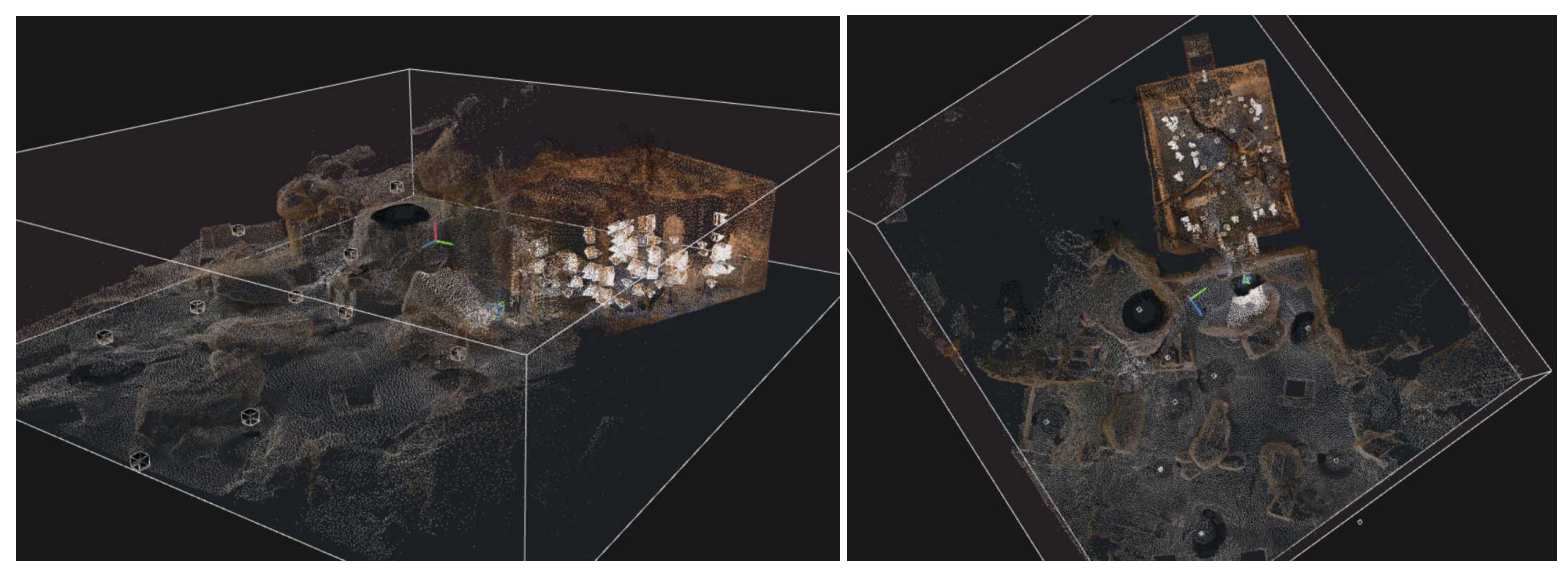

Figure 5: Alignment between the inner chamber HD pictures along with the interior and exterior scans of the tomb of Djehutihotep.

Djehutihotep. This digital tool allows for a detailed visualization of the decorated walls of the inner chapel, and the forecourt and outer chamber of the monument.

The cornerstone of VR environments development is the access to convincing, complete and realistic 3D models. That is why we based the process for the surface reconstruction of the tomb of Djehotihotep on the combination of the acquired point-clouds with the panoramic photos of the scanner and high definition images of the inner chamber. The objective behind this approach is to compute a visually convincing colorized mesh model of the tomb and its decorated elements. Therefore, the pipeline followed for the VR environment is as follows. Firstly, the points that correspond to the tomb are selected and cut out from the general model. Secondly, the HD images of the chamber are aligned with respect to the 3D points. Then, the mesh model is computed from the point-cloud and is textured using the HD imagery. Finally, the 3D model is instantiated into the VR world.

The software packages Cyclone [13], Reality Capture [23] and Blender [4] are used for data processing. Apart from the registration process, Cyclone is also used to group and export the registered tomb's scans to the 3D modeling engine, Reality Capture. This photogrammetry software package creates 3D models from different input sources (images and laser scanners) by following the following surface reconstruction work-flow: data alignment, point-cloud simplification, meshing and texture computation. Unlike other approaches that combine photogrammetry and TLS by using control points, Reality captures employs computer vision algorithms [22] to match image content of both sources (HD images and panoramic photos of the scanner), and to consequently align the photos with already registered point-clouds. Figure 5 shows the set of captured images into the same reference system of the scans. In total, 305 camera positions are considered to cover the inner chamber, enabling the software to colorize the TLS points and reconstructed mesh using the high quality texture of the images. After completing the surface reconstruction work-flow, the 3D model is processed to be uploaded to an on-line platform. Therefore, untextured spots of the mesh are colorized, and the model is simplified to fulfill size constraints by using the texture rendering and decimation simplification tools of Blender.

The final 3D model is instantiated into a VR world developed on A-Frame [1], an open-source web platform for building VR environments that allows for light rendering, camera position control, skybox generation, and more importantly, VR equipment compatibility. Since the VR worlds are implemented in Hypertext Markup Language (HTML), several application opportunities can be explored, from serious games to virtual museums. In the developed
VR world, the main goal is to bring the recorded data to experts and the general public, in such a way that the user is able to visualize and study the archaeological elements of the tomb (colorful scenes of the decorated walls, collapsed fragments, and hieroglyphics) like in a realistic scenario. The following link https://djetomb.glitch.me/ shows the Tomb of Djehutihotep in VR. Screenshots of the virtual world's desktop version are shown in Figure 6 top, and the stereoscopic visualization of the VR environment via a smartphone is depicted in Figure 6 bottom.

An important performance metric to consider when designing VR environments, is the number of frames per second (fps) that can be achieved. This is crucial for a smooth interaction between the digital entity and the user, as the VR experience highly relies on real-time data processing. Hence, the developed web-based VR environment is evaluated in terms of this performance by using firefox's performance developer tools [15]. The tools are run on a system with the following hardware characteristics: Processor intel core i7, RAM 16GB, Graphics NVIDIA Geforce 1080. The evaluation performance tool allows developers to record the activity of the browser over a period of time, and then to evaluate the website performance based on a set of metrics and activities that the browser performs to render the site. We recorded the activity of exploring the tomb of Djehutiotep in VR over $76800 \mathrm{~ms}$. The frame rate obtained over this period of time was 58.76 , the minimum 15.26 , and maximum $60 \mathrm{fps}$. Figure 7 shows the first 21.8 seconds of the experiment. It is clear that the frame rate drops are short and intermittent. The frame rate achieved is adequate for moderate-speed motion like in the case of video content, but also to avoid motion blur and disorientation.

\section{Discussion}

The presented research aims at showcasing TLS-based digital recording for heritage documentation purposes. Concretely, the case of an ancient Egyptian monument and surrounding site is studied. Our main goal was to show an initial framework towards the comprehensive digital documentation of the site. The principal deliverable of this is a goereferenced point cloud, that could serve as a basis for digital analysis tools. For instance, the acquired 3D data of the burial shafts could be leveraged for the detailed description of the monument by means of cross-sectional metric drawings. This is a potential application of the data and represents a reliable alternative to traditional archaeological description and measurements methods. In this regard, since the points are geographically located in the local coordinate system of the site, further information of the site could be derived from the acquired point-cloud, such as the correct orientation of the burial shafts and tombs, the exact 3D location of 




Figure 6: VR environment for the visualization of Djehutihotep's tomb, desktop version (top), and mobile-based stereoscopic view (bottom)

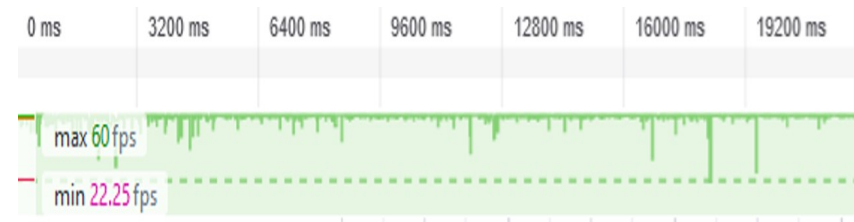

Figure 7: Frame rate performance plot of the VR world over the first 21760ms.

archaeological findings, and also it could serve as ground-truth for hand-made archaeological measurements.

The combination of TLS and photogrammetry for surface reconstruction proved to be a well-suited approach for the creation of realistic 3D models. Our research aimed at creating a 3D mesh of the most representative monument of the governor's tombs that exhibits high-spatial resolution (more than 1 million polygons) and high quality texture of the decorated elements. This will allow experts to perform a geometric analysis of the acquired data in such a way that high level information could be extracted from the mesh model. A direct application could be to automatically match and join collapsed stones together by means of extraction and matching of 3D descriptors [10]. In this way, a partial reconstruction of the site could be performed, offering archaeologist a perspective of what the monument looked like in ancient times.

The VR world of Dejehutihotep's tomb proved to be an attainable deliverable for the visualization of Heritage Sites. The convincing texture quality of the inner chamber, allows for a virtual on-site interpretation and study of the ancient scenes, hieroglyphics, and current state of the tomb. The main characteristics of this VR world are: web-based platform, plug-and-play compatibility with VR equipment, and real-time performance. On the one hand, the first two characteristics bring the VR application to the general public, since the technical learning curve is notably reduced since the VR works without installing external dependences. On the other hand, the
$59 \mathrm{fps}$ achieved ensures the realistic and comfortable visualization experience of the monument.

\section{Conclusion ANd Future Work}

A work-flow for the exhaustive digital documentation of the Governor's tombs of Dayr al-Barsha was presented. This includes the 3D recording campaign, scans processing, and data-user interaction by means of a web-based VR environment. The Physical acquisition and $3 \mathrm{D}$ representation of this Egyptian site was conducted on the basis of remote sensing techniques and sensors. A portable TLS was used to scan the archaeological monuments that make up this heritage site, including burial shafts, decorated chapels, and burial chambers. The post-processing of the acquired data resulted in a set of georeferenced points that provide an accurate and dense 3D description of the monuments. In order to show one of the potential applications of the acquired data, the point-cloud of the most impressive tomb (Djehutihotep) was combined with high resolution images of its decorated walls using photogrammetric techniques. Thus we obtained a realistic 3D model of the tomb, which was instantiated in a web-based VR world. Aside from enriching the on-site visualization experience of the monument, the VR platform offers a new alternative towards the virtual preservation of heritage sites.

Future work includes the digital recording of the remaining archaeological areas of the Governor's tombs, and the further study of its monuments via digital analysis tools. Possible examples are cross-sectional drawings of the construction features of burial shafts, accompanied with detailed information of previous and ongoing excavations, and high resolution 3D models of each tomb, blending photogrammetry with TLS point-clouds. This can lead in a later stage to a VR world of the entire zone, along with virtual educational information about the tomb's history and interpretation of decorated chapels. The final goal is the compilation of a full and comprehensive documentation of one of the most representative Egyptian middle kingdom cemeteries.

\section{ACKNOWLEDGMENTS}

\section{REFERENCES}

[1] A-Frame. A-frame. https://aframe.io/. Accessed: 2018-07-18.

[2] M. Berger, A. Tagliasacchi, L. M. Seversky, P. Alliez, G. Guennebaud, J. A. Levine, A. Sharf, and C. T. Silva. A Survey of Surface Reconstruction from Point Clouds. Computer Graphics Forum, 2017. doi: 10 $.1111 / \mathrm{cgf} .12802$

[3] E. Dall'Asta, N. Bruno, G. Bigliardi, A. Zerbi, and R. Roncella. Photogrammetric techniques for promotion of archaeological heritage: The archaeological museum of parma (Italy). International Archives of the Photogrammetry, Remote Sensing and Spatial Information Sciences ISPRS Archives, 41(July):243-250, 2016. doi: 10.5194/isprsarchives -XLI-B5-243-2016

[4] B. Foundation. Blender. https://www.blender.org/. Accessed: 2018-07-18.

[5] S. Gonizzi Barsanti, G. Caruso, L. L. Micoli, M. Covarrubias Rodriguez, and G. Guidi. 3D visualization of cultural heritage artefacts with virtual reality devices. In International Archives of the Photogrammetry, Remote Sensing and Spatial Information Sciences ISPRS Archives, vol. 40, pp. 165-172, 2015. doi: 10.5194/isprsarchives -XL-5-W7-165-2015

[6] G. J. Grenzdörffer, M. Naumann, F. Niemeyer, and A. Frank. Symbiosis of UAS photogrammetry and TLS for surveying and 3D modeling of cultural heritage monuments-a case study about the cathedral of St. Nicholas in the city of Greifswald. In International Archives of the Photogrammetry, Remote Sensing and Spatial Information Sciences ISPRS Archives, 2015. doi: 10.5194/isprsarchives-XL-1-W4-91-2015

[7] P. Grussenmeyer, E. Alby, T. Landes, M. Koehl, S. Guillemin, J. F. Hullo, P. Assali, and E. Smigiel. Recording approach of heritage sites based on merging point clouds from high resolution photogrammetry and Terrestrial Laser Scanning. International Archives of 
the Photogrammetry, Remote Sensing and Spatial Information Sciences - ISPRS Archives, 39(September):553-558, 2012. doi: 10.5194/ isprsarchives-XXXIX-B5-553-2012

[8] A. Guarnieri, F. Fissore, A. Masiero, and A. Vettore. From TLS Survey to 3D Solid Modeling for Documentation of Built Heritage: The Case Study of Porta Savonarola in Padua. ISPRS - International Archives of the Photogrammetry, Remote Sensing and Spatial Information Sciences, 2017. doi: 10.5194/isprs-archives-XLII-2-W5-303-2017

[9] G. Guidi, L. L. Micoli, S. Gonizzi, M. Brennan, and B. Frischer Image-based 3D capture of cultural heritage artifacts: An experimental study about 3D data quality. In 2015 Digital Heritage International Congress, Digital Heritage 2015, 2015. doi: 10.1109/DigitalHeritage. 2015.7419514

[10] Y. Guo, M. Bennamoun, F. Sohel, M. Lu, and J. Wan. 3d object recognition in cluttered scenes with local surface features: a survey. IEEE Transactions on Pattern Analysis and Machine Intelligence, 36(11):2270-2287, 2014.

[11] D. Hoffmeister, S. Zellmann, K. Kindermann, A. Pastoors, U. Lang, O. Bubenzer, G.-C. Weniger, and G. Bareth. Geoarchaeological site documentation and analysis of 3D data derived by terrestrial laser scanning. ISPRS Annals of Photogrammetry, Remote Sensing and Spatial Information Sciences, II-5(June):173-179, 2014. doi: 10.5194/ isprsannals-II-5-173-2014

[12] C. Karp. Digital heritage in digital museums, 2014. doi: 10.1111/muse .12069

[13] Leica Geosystems. Cyclone.

[14] K. Leuven. Website dayr al-barsha project. http://www . dayralbarsha.com. Accessed: 2018-06-13.

[15] Mozilla. Firefox performance tools. https://developer.mozilla. org/son/docs/Tools/Performance. Accessed: 2018-07-25.

[16] W. Neubauer, M. Doneus, N. Studnicka, and J. Riegl. Combined High Resolution Laser Scanning and Photogrammetrical Documentation of the Pyramids at Giza. CIPA XX International, pp. 470-475, 2005.

[17] R. Pintus, K. Pal, Y. Yang, T. Weyrich, E. Gobbetti, and H. Rushmeier. A Survey of Geometric Analysis in Cultural Heritage. Computer Graphics Forum, 35(1):1-27, 2015. doi: DOI: 10.1111/cgf.12668

[18] F. Remondino. Heritage recording and 3D modeling with photogrammetry and 3D scanning. Remote Sensing, 2011. doi: 10.3390/ rs3061104

[19] P. Rodríguez-Gonzálvez, E. Nocerino, F. Menna, S. Minto, and F. Remondino. 3D Surveying and modeling of underground passages in wwi fortifications. In International Archives of the Photogrammetry Remote Sensing and Spatial Information Sciences - ISPRS Archives, 2015. doi: 10.5194/isprsarchives-XL-5-W4-17-2015

[20] S. Rusinkiewicz and M. Levoy. Efficient variants of the icp algorithm. In 3-D Digital Imaging and Modeling, 2001. Proceedings. Third International Conference on, pp. 145-152. IEEE, 2001.

[21] H. Ruther, R. Bhurtha, C. Held, R. Schroder, and S. Wessels. Laser Scanning in Heritage Documentation: The Scanning Pipeline and its Challenges. Photogrammetric Engineering and Remote Sensing, 78(4):309-316, 2012.

[22] S. Saxena and R. K. Singh. A survey of recent and classical image registration methods. International journal of signal processing, image processing and pattern recognition, 7(4):167-176, 2014.

[23] C. R. s.r.o. Reality capture. https://www.capturingreality. com/. Accessed: 2018-07-18.

[24] D. Suwardhi, F. Menna, F. Remondino, K. Hanke, and R. Akmalia. Digital 3D Borobudur - Integration of 3D Surveying and Modeling Techniques. In The International Archives of the Photogrammetry, Remote Sensing and Spatial Information Sciences, 2015. doi: 10.5194/ isprsarchives-XL-5-W7-417-2015

[25] G. Tucci, V. Bonora, A. Conti, and L. Fiorini. High-Quality 3D Models and Their Use in a Cultural Heritage Conservation Project. ISPRS International Archives of the Photogrammetry, Remote Sensing and Spatial Information Sciences, XLII-2/W5(September):687-693, 2017. doi: 10.5194/isprs-archives-XLII-2-W5-687-2017

[26] H. Willems. Dayr al-Barsha, Volume I: The Rock Tombs of Djehutinakht (No. 17K74/1), Khnumnakht (No. 17K74/2), and Iha (No. 17K74/3). With an Essay on the History and Nature of Nmarchal Rule in the Early Middle Kingdom, vol. 1. Peeters, Leuven, 2007. Orientalia
Lovaniensia Analecta 155.

[27] F. Zvietcovich, B. Castaneda, and R. Perucchio. 3D solid model updating of complex ancient monumental structures based on local geometrical meshes. Digital Applications in Archaeology and Cultural Heritage, 2014. doi: 10.1016/j.daach.2015.02.001 